\title{
Factors Contribute To Slow Internet Adoption in Omani Private Sector Organizations
}

\author{
Khamis Al-Gharbi and Rafi Ashrafi \\ Department of Information Systems, College of Commerce \& Economics, Sultan Qaboos University, Oman
}

\begin{abstract}
The study explores the reasons for the slow adoption of Internet technologies in Omani private sector organizations. A survey questionnaire was used to collect data from 60 private Omani organizations. One of the main factors for not adopting internet technologies was that internet is not relevant to their business. An insufficient level of demand for purchasing through Internet, lack of availability of skilled employees and security concerns were cited as the main factors for not adopting Internet in Omani organizations. The study also reveals that negative attitudes of business decision makers about the use and benefits of internet maybe a major obstacle in adopting Internet in their businesses. Furthermore there is no correlation between the organization size and the adoption of the Internet. In addition to that, Omani businesses prefer face to face interaction with their customers.
\end{abstract}

Keywords: Internet, Adoption, Oman.

\section{Introduction}

The emergence of Internet technologies has opened new opportunities for companies of all sizes to conduct business efficiently and effectively. Internet technologies have the potential to open up the global market thereby opening new doors for growth of organizations. The literature and research suggests that the Internet offers a number of benefits for organizations to compete at a national and international level. Despite of a number of benefits associated with Internet technologies, a number of companies in developing countries have been slow and conservative in adopting and subsequently slowing the diffusion of it. Our study also reveals that there are a number of reasons that contribute to the reluctance of adoption of Internet technologies. We aim to investigate the reasons for the slow intake of the Internet and related technologies and the adoption and diffusion of Internet in the Omani private sector organizations. We also wanted to identify factors inhibiting and facing Omani private sector organizations from adoption and use of Internet technologies. Although the research context is quite specific, it is believed that the findings will be relevant to other organizations in general and to developing countries in particular. The literature and research related to the use of Internet technologies in e-business and ecommerce activities has been dominated by an examination of its relevance to the enterprises in developed countries. However, there is a lack of research on companies in developing countries regarding this issue. Furthermore, most of the scarce studies that have been conducted in developing countries regarding the use of ICT (Information and Communication Technology) and e-business are based on anecdotal and case studies therefore very little statistical data is available (UNCTAD, 2004). This research is an attempt to fill that gap and to gain a better understanding of why the adoption of Internet technologies has been slow in Omani

Copyright (C) 2010 Khamis Al-Gharbi and Rafi Ashrafi. This is an open access article distributed under the Creative Commons Attribution License unported 3.0, which permits unrestricted use, distribution, and reproduction in any medium, provided that original work is properly cited. Contact author: Khamis Al-Gharbi e-mail: algharbi@squ.edu.om 
organizations, and identifying the various factors inhibiting its adoption by these organizations.

\section{Benefits of the Internet Technologies}

The literature review suggests that there are a number of benefits in adopting Internet technologies. According to Porter (2001) "the key question is not whether to deploy Internet technology--companies have no choice if they want to stay competitive". Porter (2001) implicitly stated that companies that are ignoring this powerful tool will not have the ability to compete successfully in the global business environment. Furthermore, Porter (2001) made a comparison between previous technologies and the Internet and argued that Internet technology provides "better opportunities for companies to establish distinctive strategic positioning than it did in the previous generation of information technology" (pp. 64). Czerniawska and Potter (1998) stressed that companies ignoring Internet technologies and e-business concepts may lose opportunities to gain a competitive edge. Also, Papaioannou and Dimelis (2007) found a positive and significant impact of ICT on productivity growth.

Companies can take advantage of the opportunities provided by Internet technologies in order to have direct links with customers, suppliers, and distributors. The Internet also enables companies to develop new products and services for new and existing customers (Walters and Lancater, 1999). Marketing products and services to new customers and new markets can be a problem especially for SMEs (Small Medium Enterprises) due to the lack of experience and resources. However, the Internet offers opportunities for companies to market their products and services around the world without having to physically contact or advertise to customers (Karakaya and Karakaya,1998; Tiessen et al., 2001). Organizations competing in dynamic competitive environments are struggling to achieve effectiveness and efficiency, implementation of Internet technologies may help those companies in this regard. Porter (2001) argued that the Internet is the most powerful tool available nowadays as it offers operational effectiveness via easing and speeding the transfer and exchange of real-time information. The four principal factors that make the adoption and diffusion of Internet technologies in the area of e- business and e-commerce attractive are: (1) reducing transaction costs (Kalakota and Whinston, 1996); (2) providing better services to customers (Barney, 1991); (3) meeting consumer demands (Chatfield and Bjorn-Anderson, 1997); and (4) creating efficient transactions (Mata et al., 1995). Literature review suggests that the emergence of the Internet allows companies in general and SMEs in particular to compete efficiently and effectively in the national and international markets (Schmid et al., 2001).

\section{Adoption of Electronic Business}

The dissemination and acceptance of a new technology in a market or among parties in an industry is often referred to as diffusion (Rogers, 1983). The diffusion model developed by Rogers (1983) is represented by an S-curve model. The behavior of the company towards the diffusion of innovation ranges from innovators to laggards, deciding the steepness of the curve (Chaffey, 2007). According to Rogers (1983) there is a continuum of approaches of how companies deal with technological innovation.

One approach to adoption is to be a leader in adopting new technology. Early adopters are always the first ones to make use of technologies to gain competitive advantage. However, the problem with being first in adopting technologies may turn to be the 'bleeding edge' due to the risk of failure (Bocij et al., 2006; Chaffey, 2007). The early adopter approach can be characterized by high risk in the case of failure and high reward in the case of success since early adopters can gain an edge over their rivals. Usually there is small number of organizations who use this approach.

The second approach towards innovation diffusion is a conservative approach which means wait and see and do not adopt or use the technology until its benefits have been successfully demonstrated by other adopters (Bocij et al., 2006; Chaffey, 2007). Generally, a majority of organizations wait and see until the technology get wide acceptance and they are convinced of the benefits of the use of technology. 


\section{Barriers in Adoption of Internet and e-Business}

Clarke (2000), Chen et al. (2006), and Chaffey (2007) identified a number of barriers to ebusiness adoption such as: lack of established theories, instability of phenomena, variations in culture, low-level investments in IT, lack of resources and skilled workforce, and limited growth strategies. The adoption of Internet technologies and e-business by SMEs has been slower in comparison to large companies worldwide (Marshall et al., 2000). Chaffey (2007) reported that $40 \%$ of SMEs in Europe did not have a web site and that majority did not use intranets, extranets, online purchasing or e-government services. In a survey conducted by Simes (2002) it was clear that SMEs lack ICT adoption due to the lack of awareness and knowledge of its benefits.

A research on electronic data interchange conducted by Iacovou et al. (1995) showed perceived benefits, organizational readiness, and external pressure barriers that affect rate of adoption. In addition to the above barriers, OECD (1998) identified two main reasons for SMEs not adopting e-commerce. The reasons are unfamiliarity with the technology, and concerns regarding cost and security. UNCTAD (2004) found that low use of e-payments is due to security concerns. Furthermore, DTI (2000) conducted a survey across Europe to identify barriers to the development of online technologies. DTI (2000) found that set-up cost and running costs are the top two barriers. Also, lack of skills, resources and knowledge are among the other top barriers (DTI, 2000). However, it have been argued that these barriers to the diffusion of Internet technologies in e- business and e-commerce vary considerably within various contexts, such as different cultures, countries and organizations.

Adoption of Internet and e-Business in Developing Countries

There has been a lack of research to investigate the barriers inhibiting the diffusion of the Internet in e-business and e-commerce in developing countries' organization. El-Nawawy and Ismail (1999) conducted a study of e-commerce adoption in Egypt. They found that the main factors that contributed to the lack of adoption of e-commerce in Egypt were awareness and education, market size, e-commerce infrastructure, telecommunications infrastructure, financial infrastructure, the legal system, the government's role, pricing structures, and social and psychological factors. Another study conducted by Kapurubandara and Lawson (2006) investigated the barriers inhibiting SMEs in Sri Lanka from adopting ICT and e-commerce. They proposed a framework which contains two kinds of barriers: internal and external. Internal barriers can be controlled by the company and include barriers such as lack of time and resources, and lack of awareness on the part of owner/manager. Also it includes cost and return on investment. External barriers cannot be controlled by the company and include barriers such as inadequate telecommunication infrastructure, social and culture, political and legal and regulatory factors. Both of the above studies have investigated barriers that inhibit the organizations in developing countries from adopting and utilizing Internet technologies in the area of e-business and e-commerce.

\section{Background on Oman}

Oman is a developing country located on the south east of the Arabian Peninsula. Oman is the second largest country among the Gulf states after Saudi Arabia. It is spread over 309,500 square kilometers and has a 1,700-kilometre coastline. Since the accession of Sultan Qaboos in 1970 to the throne, there has been remarkable progress in different fields such as economy, politics, education, and the civil services. The modernization and restructuring of the administrative systems of the civil service as a result of the continuous progress has been vital in term of the changing circumstances and future requirements. Oman enjoys a stable political, economic, and social system. Oman has achieved remarkable progress, both socially and economically, with the implementation of a series five-year development plans. Oman has a population of 3.1 million residents that sparsely populate the country at 8.6 inhabitants per $\mathrm{km}$. A distinguishing feature of the country is its young population (ages 15 and under) which currently accounts for $50 \%$ of the total population.

\section{ICT Sector in Oman}

According to the United Nation 2008 EGovernment Readiness Report, Oman has jumped 
up to 28 points in this ranking position from 112th position in 2005 to 84th position in 2008 . Oman ranks 60th position in the e-Participation Index (out of 192 countries) with an index value of 0.2045 . The number of Internet subscribers and mobile subscribers are rising dramatically over the past few years (Naqvi and Al-Shihi, 2009). This rise is a reflection of "the pace of progress through initiatives to build of ICT infrastructure, over electronic services and build capacity within the country to harness the power of technology" (Information Technology Authority, 2009).

\section{Research Methodology}

The aim of the paper is to investigate reasons for the slow adoption of the Internet and related technologies in the Omani private sector organizations. Furthermore, one of the objectives of the research is to identify factors inhibiting Omani private sector organizations from adoption of Internet technologies. A questionnaire survey was used to collect data from private Omani organizations. The survey questionnaire was used for the following reasons:

- The ability to detect relationships that are common across the organizations and to therefore provide general statements about the study (Gable, 1994).

- It exhibits considerable precision in collecting and reporting data (Bryman, 1996; Gonzalez, 1998; Remenyi and Williams, 1995).

- It is considered to be an inexpensive approach to gather data (Remenyi and Williams, 1995).

- It generally offers the anonymity that may lead participants to be more open and truthful (Al-Assaf, 1997; Al-Shuabi, 1991).

The use of the questionnaire also has advantage of overcoming many cultural factors. For example, it is part of the Arab culture that personal and family or business information should not be discussed outside the boundaries of the family or the company as such matters are viewed as being very private (Al-Qahtany, 1996). The respondents, therefore, may hold greater credibility as they do not have to identify themselves or their organizations.
The questionnaire consists of six parts: size of the organization, views on the use of Internet, reasons for not adoption, plan for future adoption, and if so, what business applications they plan to use. The last section of the questionnaire was related to the Internet security concerns.

\section{Data Analysis and Results}

Data was collected from 60 organizations who have not adopted internet technologies.

There is no official definition of SMEs in Oman. For the purpose of this research we use the following definition of SMEs also adopted by other studies (Kapurubandara et al 2006)

Micro organization: less than 10 employees, Small Organization: between 10 and 50 employees, Medium organization: between 50 and 250 employees, and Large organization: over 250 employees.

\section{Size of Organizations}

Figure 1 shows that $17 \%$ of the Micro organizations, $20 \%$ of the Small organizations, $28 \%$ of Medium organizations and $35 \%$ of the large organizations the organizations surveyed in this study have not adopted Internet technologies. It is surprising to note that $35 \%$ of the organizations are large organizations.

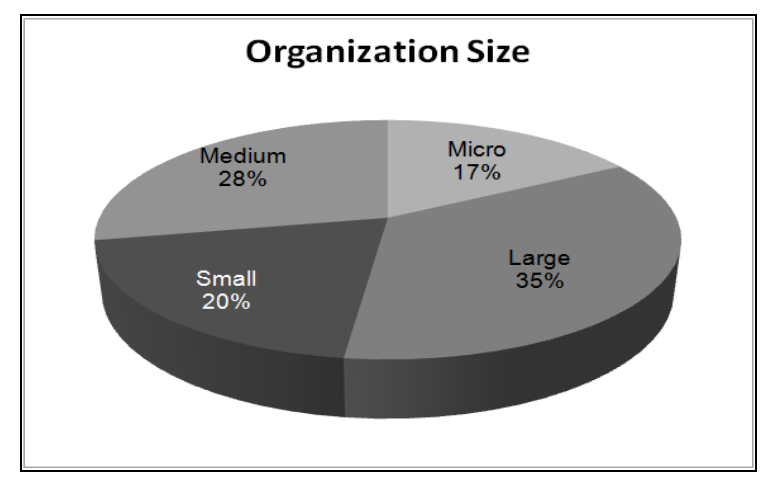

Figure 1 Size of organizations 


\section{Attitudes and opinions towards the Internet adoption}

Figure 2 shows six statements that investigated participants' attitudes and opinions toward the Internet. Through these six statements we wanted to investigate if there is a direct linkage between the attitudes and opinions of decision making and the adoption of the Internet in their organizations. Do the respondents' attitudes and opinions influence the decisions that have been taken or will be taken regarding the Internet adoption?

Figure 2 shows that more than $85 \%$ of the participants think the Internet is not suitable for their companies' use and $74 \%$ think that the
Internet is only for technical people. Furthermore, Figure 2 shows $86 \%$ of the respondents disagree that the Internet is "an important way of conducting business". Figure 2 also shows that $78 \%$ of the respondents disagree that the Internet is "an important tool to enhance company image". Also, $86 \%$ of the respondents disagree that the Internet is "an effective communication tool" and $51 \%$ think that the Internet has little chance of success in their business.

This suggests that negative attitudes and opinions regarding the Internet within the Omani organizations have led the decision makers not to adopt the Internet within the Omani organizations.

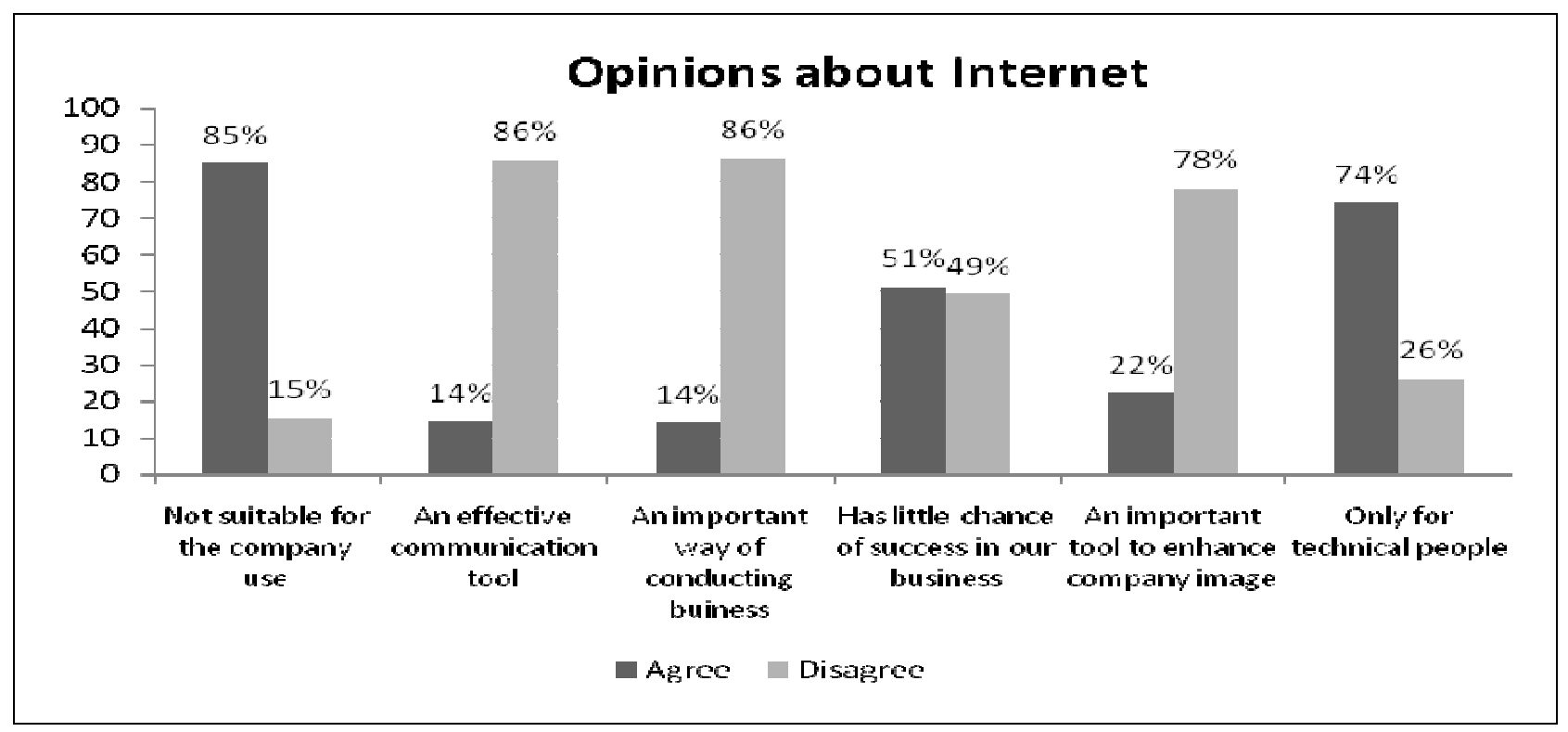

Figure 2: Opinions about Internet

\section{Reasons for non-adoption of Internet}

Figure 3 show that $42 \%$ of organizations feel that Internet is not relevant to their business. While $40 \%$ of the respondents mentioned that there is insufficient level of demand for purchasing through Internet and $40 \%$ also mentioned that there is a lack of skilled employees to develop, maintain and/or use the Internet technology. About 32\% have mentioned set up costs, 28\% running costs, and $27 \%$ lack of implementation time as the main reasons for non-adoption. Also, $25 \%$ mentioned difficulty in integrating IT systems, $23 \%$ security concerns and lack of leadership, $22 \%$ lack of management support, and $20 \%$ have privacy concerns. 


\section{Reasons for Not Adopting the Internet}

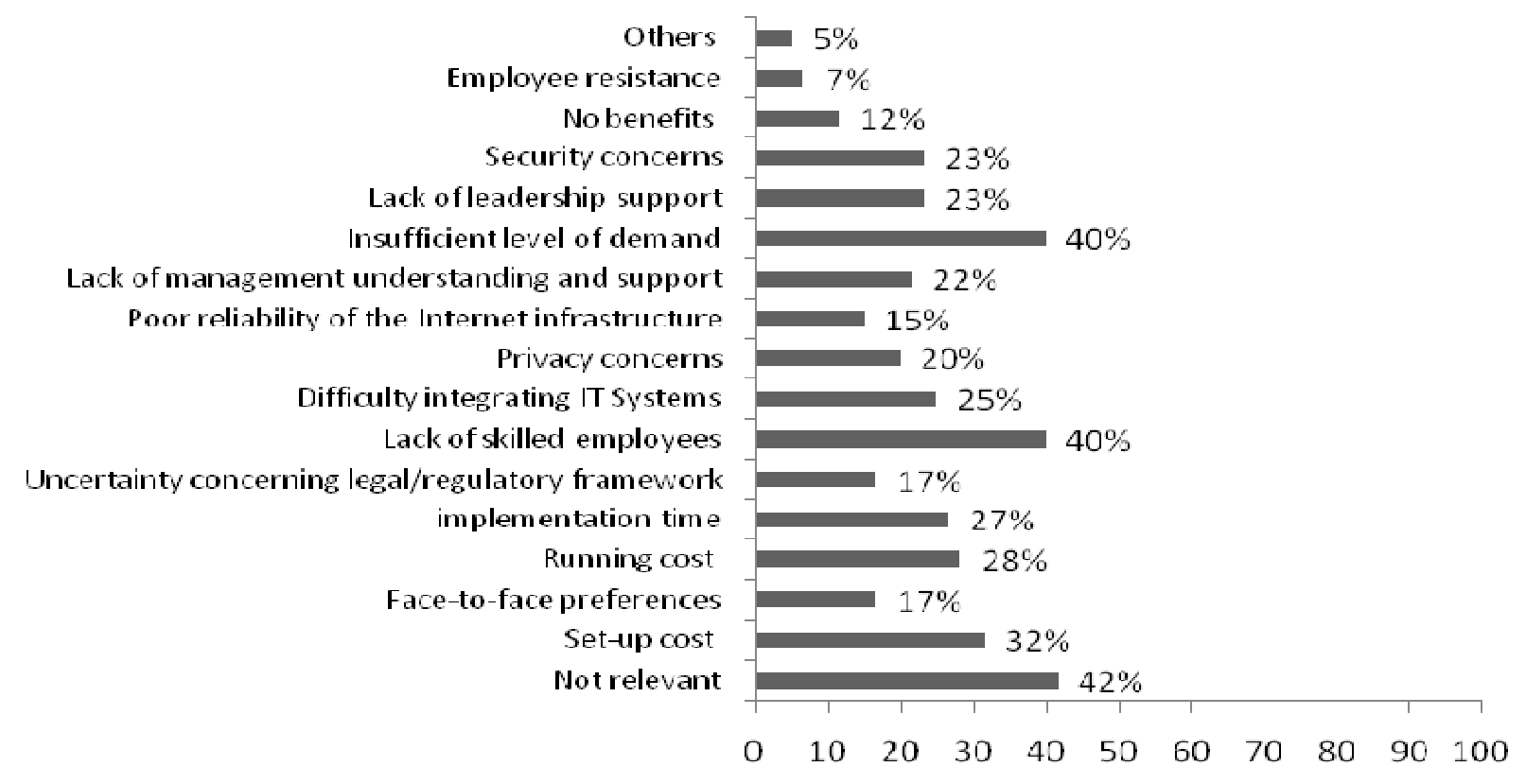

Figure 3: Reasons for not adopting Internet

Figure 3 shows that there are a number of barriers preventing Omani organizations from adopting the Internet. The five major barriers are: Internet is not relevant to their business, lack of skilled employees, insufficient level of demand for purchasing online, set up costs and running costs. Seventeen percent of the participants feel that face to face interaction with customers is the preferred mode to conduct business successfully within the Omani culture. Another influencing factor is the lack of qualified technical staff (lack of skilled employees) within the Omani organizations that are capable of implementing and maintaining Internet technologies.

\section{Future plans for adopting Internet}

Figure 4 show that $73 \%$ of respondents have future plans for adopting Internet within next 3-5 years. It shows that for whatever reasons they may not have adopted Internet yet, but they realize the importance of using Internet in their business and are planning to introduce it within the next 3 to 5 years. $27 \%$ have no plans to adopt the Internet in the near future.

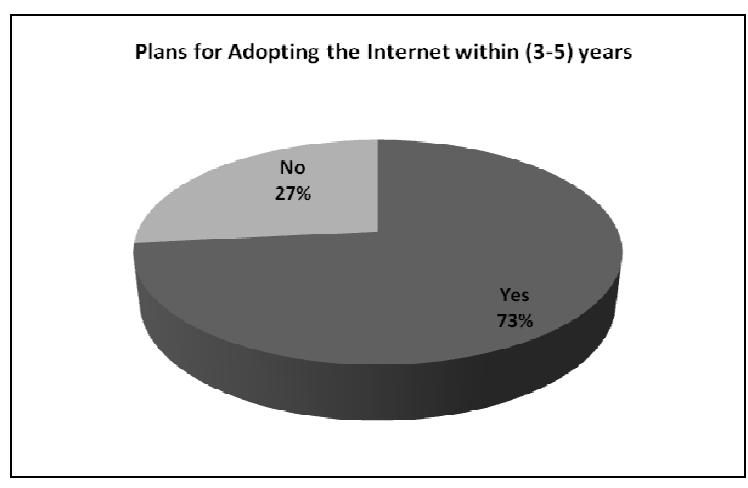

Figure 4 Future plans for Internet Adoption 


\section{Use of Business Applications in the Future}

Figure 5 shows that $42 \%$ of respondents would like to use the Internet for marketing and supply chain management. Other major reasons include procurement (21\%) and auctions (20\%). This shows that organizations in Oman have awareness about the market opportunities Internet can offer to their business and have plans to use applications that can help their business to be more competitive.

\section{Business application for adopting the Internet}
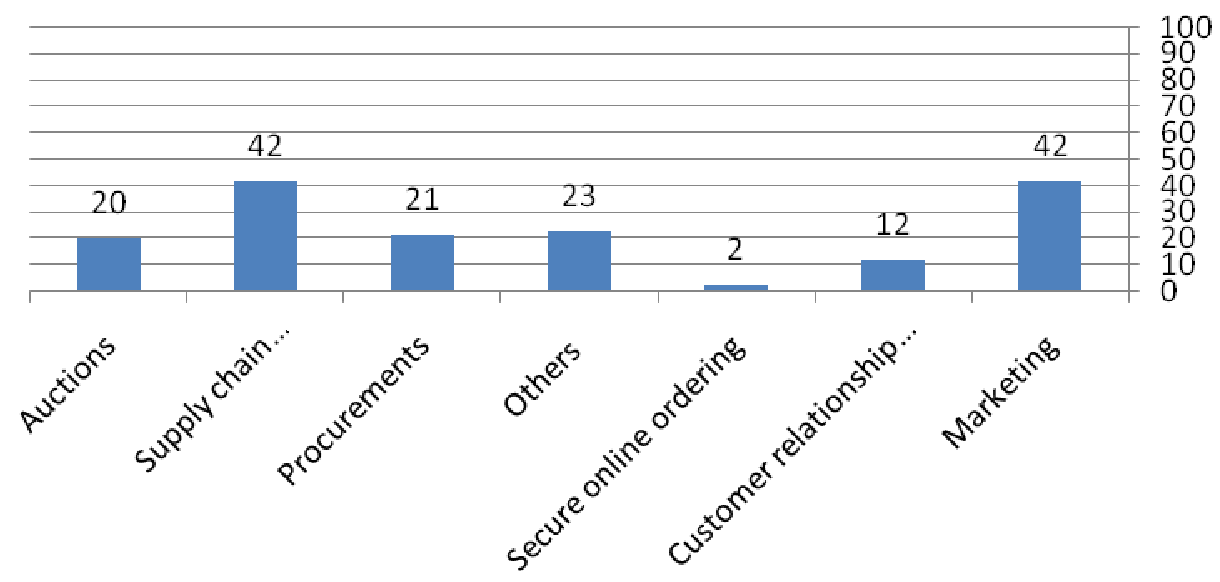

Figure 5 Business applications planning to use in future

\section{Security of Payments}

Security of online transactions is a major concern worldwide and Oman is not an exception. Figure 6 reveals that on aggregate $69 \%$ of respondents are not confident about online payment security. It also shows that $18 \%$ of correspondents feel that the online payment is not secure, $23 \%$ of the participants feel that the security needs to be enhanced, and $3 \%$ of the respondents feel that it is only partially secure. Also shown in Figure 6 is that $25 \%$ of the participants are not sure about the security of online and only $29 \%$ of the respondents think it is secure. This finding may be related to the other barriers facing Omani organizations in the implementation of the Internet technologies such as uncertainty concerning legal/regulatory framework for selling/buying over the Internet (shown in Fig 3). The implication for decision makers and IT professionals is to enhance the security of online payment and to assure and educate the people about conducting online transactions. The implication for the government in Oman is to introduce the needed laws dealing with the issue in order to build and strengthen the trust in online business. 


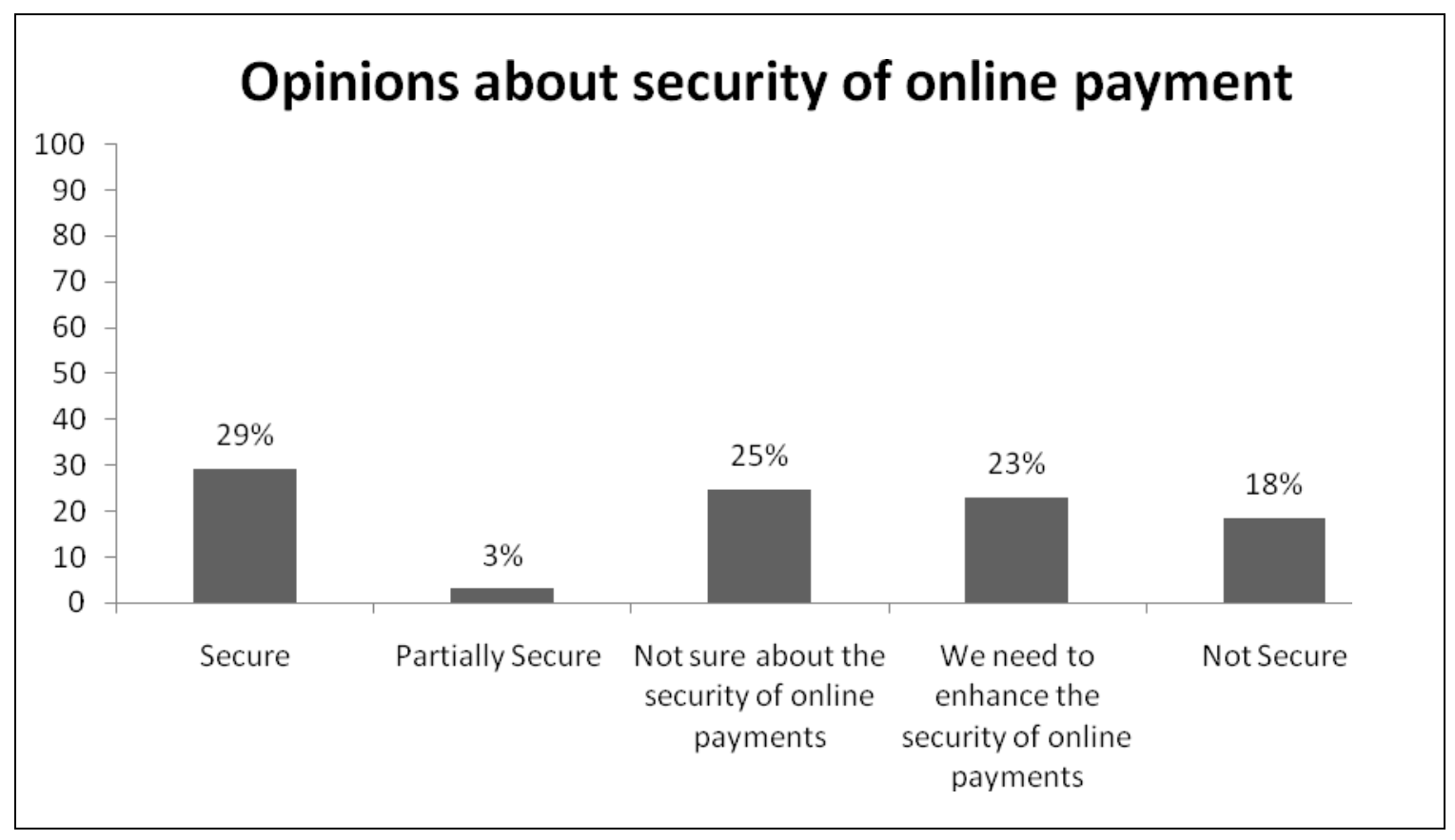

Figure 6: Opinins about online security

\section{Discussion and Conclusion}

The study presented in this paper provides evidence that Omani organizations have been slow in adopting Internet technologies. One of the main reasons reported was that Internet is not relevant to their business. It seems that there is a lack of awareness of the benefits of using Internet. This finding is in line with other previous studies.

Generally, SMES are slow in adopting Internet for various reasons including lack of resources. However, one of the interesting results of the study is that about one third of large organizations in Oman have not yet adopted Internet in their business. This shows that there is no direct relation between the size of the organization and the adoption of the Internet in Omani businesses. This may be due to cultural differences.

There seems to be a cultural difference among the businesses in Oman as compared to the Western culture. Omani businesses regard face-to-face interaction with the customers as the best mode of conducting their business. Perhaps, as in other parts of world, the elder generation is not comfortable with using the Internet which may contribute to the lack of critical mass of people using the Internet for business. However, as the use of computers and Internet in general public is increasing, and the government's initiatives to digitize Oman and to provide services to its citizens and businesses are being implemented, we feel that the situation will change in the near future. This is evidenced by almost three quarters of the organizations have future plans for adopting the Internet in the next 3-5 years.

The study shows that in spite of not having adopted the Internet, yet, organizations realize the significance of using Internet in their business. Only a minority of organizations have no plans whatsoever to adopt the Internet in the near future. Organizations that plan to adopt the Internet would like to use it predominantly for marketing and supply chain management. Others would like to use the Internet for procurement and auctions. This shows that organizations in Oman have an awareness about the market opportunities the Internet can offer their business and have plans to use applications that can help their business become more competitive.

Security of online transaction is a major concern in Oman. Majority of respondents consider online payments to be rather insecure. Only a fraction of the respondents think it is secure. The Omani government is aware of this concern and is working to have a safe e-payment gateway for businesses and citizens. This will increase confidence in public and business to conduct online payment safely. 
One the findings of the research seems to be there is a direct link between the attitudes and opinions of decision making and the adoption of the Internet in their organizations. Majority of the participants in those companies that have not adopted Internet think that Internet is not suitable for their companies' use and it is only for technical people. These results suggest that negative attitudes regarding the Internet have led the decision makers not to adopt the Internet within the Omani organizations.

\section{References}

AL-Assaf. 1997. 'Computer-Based Information Systems in the Role of Information Technology Manager in Saudi Arabia', Ph.D. Thesis, University of Manchester.

AL-Qahtany, S. 1996. 'Management Development in Saudi Arabia: The Preparation for Borderless World', Ph.D. Thesis, University of Leicester.

AL-Shoaibi, A. 1998. 'The Impact of Information Technology on Organisations: The case of Saudi Private Sector', Ph.D. Thesis, University of St Andrews.UK.

Barney, J. 1991. 'Firm Resources and Sustained Competitive Advantage', Journal of Management,17: 771-792.

Bocij, P., Chaffey, D., Greasley, A., and Hickie, S. 2006. Business Information Systems, $3^{\text {rd }}$ Edition, Financial Times Prentice Hall, Harlow.

Chaffey, D. 2007. E-Business and E-Commerce Management, 3rd edition, Financial Times Prentice Hall, Harlow.

Chatfield, A.T. and Bjorn-Anderson, N. 1997. 'The Impact of IOS-Enabled Business Process Change on Business Outcomes: Transformation of the Value Chain of Japan Airlines', Journal of Management Information Systems, 14(1): 13-40.

Chen, Y., Chen, H. Huang, W., Ching, R. 2006. 'EGovernment Strategies in Developedand Developing Countries: An Implementation Framework and Case Study', Journal of Global Information Management, 1(14): 23-46.

Clarke, R. 2000. 'Appropriate research methods for electronic commerce'. Available from http://www.anu.edu.au/people/Roger.Clarke/EC /ResMeth.html.

Czerniawska, F. and Potter, G. 1998. Business in a virtual world: Exploiting information for competitive advantage, MacMillan Press, London.

DTI (2000) 'Business in the Information Age International Benchmarking Study', UK Department of Trade and Industry.

El-Nawawy, M. N. and Ismail, M. M. 1999. 'Overcoming Deterrents and Impediments of Electronic Commerce in Light of Globalization: The case of Egypt', In Proceedings of the 9th Annual Conference of the Internet Society, INIT 99, San Jose, USA, 22-25.

Gable, G. G. 1994. 'Integrating case study and survey research methods: an example in information systems'. European Journal of Information Systems, 3(2): 112-126.

Gonzalez, J. S. 1998. The 21st- Century Intranet, Prentice-Hall, Inc, NJ.

Iacovou, C.L., Benbasat, I. \& Dexter, A. 1995. 'Electronic data interchange and small organizations: adoption and impact of technology'. MIS Quarterly, 19, (4): 466-485.

Information Technology Authority. 2009, 'About ITA', available from http://www.ita.gov.om/ITAPortal/ITA/About IT $\underline{\text { A.aspx }}$

Kalakota and Whinston, 1996. 'Electronic Commerce Information Resource (ECIR) What is Electronic Commerce?' available from http://worldserver.pipex.com/yearx/yxwhatis.htm

Kapurubandara, M, and Lawson, R. 2006. 'Barriers to adopting ICT and E-commerce with SMEs in developing countries: An exploratory study in Sri Lanka', Proceedings of the Conference of CollECTeR, Adelaide: 1-13.

Karakaya, F., Karakaya, F. 1998. 'Doing business on the Internet', SAM Advanced Management Journal, 63(2): 10-14.

Love P.E.D and Irani Z. 2003. 'A project 
management quality cost information system for the construction industry'. Information and Management, 40(7): 649-661

Marshall, P., Sor, R. and McKay, J. 2000. 'An industry case study of the impacts of electronic commerce on car dealerships in Western Australia', Journal of Electronic Commerce Research, 1(1): 1-16.

Mata, F.J., Fuerst, W.L. and Barney, J.B. 1995. 'Information Technology and Sustained Competitive Advantage: A Resource-Based Analysis', MIS Quarterly, 19(4): 487-505.

Ministry of National Economy-Oman. 2008. Monthly statistically bulletin, 19(4).

Naqvi, S. J. and AL-Shihi, H. 2009. 'M-Government Services Initiatives' in Oman', Issue in Informing Science and Information Technology, 6: 817-824.

OECD (2000). The Bologna Charter on SME Policies, Organization for Economic Co-operation and Development, available from http://www.oecd.org/document/17/0,2340,en 2 $649201185180910511111,00 . h t m l$

Papaioannou, S. K. and Dimelis, S.P. 2007. 'Information Technology as a Factor of Economic Development: Evidence from Developed and Developing Countries', Economics of Innovation and New Technology, Taylor and Francis Journals, 16(3): 179-194.

Porter, M. E., 2001. 'Strategy and the internet'. Harvard Business Review, 79(3): 63-78.

Remenyi, D. and Williams, B. 1995. Some aspects of methodology for research in information systems, Journal of Information Technology, 10: 191-201.

Rogers, E. 1983. Diffusion of Innovation, 3rd Edition, Free Press, New York.

Rovere, R. L. 1998. Diffusion of information technologies and changes in the telecommunications sector, Information Technology \& People, 11(3): 194-206.

Schmid, B., Stanoevska-Slabeva, K., and Tschammer, V. (Ed.) 2001. 'Towards the E-Society
: E-commerce, E-business, and E-government', Kluwer Academic Publishers, Boston.

Simes, J. B. 2002. 'SMEs adoption of ICT sluggish'. Computerworld Philippines. Metro Manila: 1.

Tiessen, J., Wright, R. and Turner, I. 2001. 'A model of e-commerce use by Internationalising SMEs', Journal of International Management. 7(3): 211 233.

UNCTAD. 2004. 'E-Commerce and Development Report 2004', United Nations Conference on Trade and Development, United Nations, New York and Geneva: 1-224.

Walters, D. and Lancater, G. 1999. 'Using the Internet as a channel for commerce', Management Decision, 37(10): 800-816. 